\title{
Canonical validation of a modeling strategy for carbon monoxide emissions in staged operation of gas turbine combustors
}

\section{Original article}

Article history:

Submission date: 3 February 2020

Final revision date: 16 August 2020

Acceptance date: 21 September 2020

Publication date: 13 November 2020

Check for updates

*Correspondence:

NK: klarmannatd.mw.tum.de

\section{Peer review:}

Single blind

\section{Copyright:}

(C) 2020 Klarmann and Sattelmayer @) This is an open access article distributed under the Creative Commons Attribution License (CC-BY 4.0), which permits unrestricted use, distribution, and reproduction in any medium, provided the original work is properly cited and its authors credited.

\section{Keywords:}

combustion; CFD; emissions; gas turbines

\section{Citation:}

Klarmann N., Sattelmayer T. (2020).

Canonical validation of a modeling strategy for carbon monoxide emissions in staged operation of gas turbine combustors. Journal of the Global Power and Propulsion Society. 4: 161-175.

https://doi.org/10.33737/jgpps/127716

\author{
Noah Klarmann ${ }^{1, *}$, Thomas Sattelmayer $^{1}$ \\ ${ }^{1}$ Lehrstuhl für Thermodynamik, Munich, Germany
}

\begin{abstract}
Canonical validation of a holistic modeling strategy for the prediction of CO emissions in staged operation of gas turbine combustors is subject of this study. Results from various validation cases are presented. Focus is on operating conditions that can be considered typical for modern, flexible gas turbines that meet the requirements of the upcoming new energy age. Reducing load in gas turbines is usually achieved by redistributing fuel referred to as fuel staging. Fuel-staged operation may lead to various mechanism like strong interaction of the flame with secondary air leading to quenching and elevated $\mathrm{CO}$ emissions and is - due to technical relevance stressed in this work. In the recent past, our group published a new modeling strategy for the precise prediction of heat release distributions as well as $\mathrm{CO}$ emissions. An extension to the $\mathrm{CO}$ modeling strategy that is of high relevance for the introduced validation cases is addressed by this work. The first part of this study presents relevant aspects of the overall modelling strategy. Furthermore, a validation of the models is shown to demonstrate the ability of precisely predicting $\mathrm{CO}$ in two different multi-burner cases. Both validation cases feature a silo combustion chamber with 37 burners. The burner groups are switched off at partial load leading to intense interactions between hot and cold burners. Major improvement in comparison to $\mathrm{CO}$ predictions from a flamelet-based combustion model can be achieved as the modeling strategy is demonstrated to be capable of predicting global $\mathrm{CO}$ emissions accurately. Furthermore, the model's precision in fuel staging scenarios are demonstrated and discussed.
\end{abstract}

\section{Introduction}

Conventional power sources are anticipated to lose relevance due to a significant increase of renewables but will retain its major role in the overall energy mix. Besides advantages for the environment, it is worth noting that renewables will also become the best economical choice for most countries. Thus, two thirds of the global investment for power plants is expected to be spent on renewable power production (International Energy Agency (IEA), 2017). Furthermore, renewables will account for $40 \%$ of the total increase in primary energy sources (U.S. Energy Information Administration, 2017; British Petroleum (BP), 2018). While the proportion of oil and coal is predicted to decline, the use of natural gas is anticipated to increase significantly by 45\% between today and 2040 (International Energy Agency (IEA), 2017). In order to meet the increased demand for natural gas, new exploration and production techniques need to be developed 
(International Energy Agency (IEA), 2014). But what actually causes natural gas to gain importance in the next decades? There are numerous obvious reasons such as efficiency and environmental legislations like emission limits. A further reason is that power production by gas turbines plays a key role in the process of implementing a large share of renewables. Especially small- to mid-sized gas turbines are able to quickly change their load as mentioned by Wiedermann (2010). Volatilities of renewable power production cause fluctuations that need to be compensated in order to guarantee a stable public grid frequency. Besides compensation by changing the load in terms of secondary control, gas turbines also act as primary control systems. Due to these properties, gas turbines are the ideal counterpart to renewables and are thus a sustainable technology as mentioned by Sinn (2017). In order to prepare gas turbines for the challenges of tomorrow, reduction of emissions, increase of flexibility, efficiency, and reliability is of high technical relevance. To fulfil their new role, modern gas turbines need to be able to perform fast load changes in a large operating window. Load flexibility is hence an essential feature for meeting the requirements of tomorrow and therefore frequently subject of various studies. Note, load changes in gas turbines are achieved by adjusting the fuel supply as mentioned by Sattelmayer (2010). A simultaneous reduction of the air mass flow can be accomplished to a certain degree by adjusting the compressor's guide vanes as discussed by Möning and Waltke (2010). Once the minimum air mass flow is reached, a further reduction in load leads to a decrease of the global fuel-to-air ratio and colder flames. Note that nitrogen oxide $\left(\mathrm{NO}_{\mathrm{x}}\right)$ is mainly a function of temperature according to the Arrhenius law. The key difference between $\mathrm{NO}_{\mathrm{x}}$ and carbon dioxide $(\mathrm{CO})$ is that the latter is an intermediate species in hydrocarbon-based combustion. CO usually reaches a maximum within the flame that is orders of magnitude higher than the limits given by emission legislations. The burnout of $\mathrm{CO}$ is hence a mandatory step to reduce CO emissions. Super-equilibrium CO may occur in cold conditions as the temperature-sensitive burnout of $\mathrm{CO}$ cannot be completed. Under conditions that show sufficiently high temperatures, the burnout is fast and the reactive flow quickly approaches equilibrium. Below a specific flame temperature, the equilibrium state can no longer be reached, and $\mathrm{CO}$ emissions rise sharply. The lower limit of fuel reduction is given by the lean blowout event. The contrary trends in $\mathrm{CO}$ and $\mathrm{NO}_{\mathrm{x}}$ as a function of $\mathrm{T}_{\mathrm{ad}}$ may lead to a narrow range of possible operating conditions. An example is given by Lefebvre and Ballal (Lefebvre and Ballal, 2010) who stated that flame temperatures between $1670 \mathrm{~K}$ and $1900 \mathrm{~K}$ are ideal to obtain $\mathrm{NO}_{\mathrm{x}}$ values below $15 \mathrm{ppmv}$ and $\mathrm{CO}$ values below 25 ppmv. There are several strategies for augmenting the operating window towards lower loads while keeping $\mathrm{CO}$ emissions below a certain threshold. For instance, an adjustable combustor geometry can be employed to control the flame temperature by air staging (Lefebvre and Ballal, 2010). The strategy is to increase air mass flow at full load to cool the burnout area and prevent the oxidation of dinitrogen $\left(\mathrm{N}_{2}\right)$ to $\mathrm{NO}_{\mathrm{x}}$. At part-load conditions, air is reduced to increase the temperature in order to ensure $\mathrm{CO}$ burnout. However, the operation of a variable combustor geometry is complex and its industrial employment is rare (Lefebvre and Ballal, 2010). A more practical approach to extend the range of possible operating conditions is to stage fuel instead of air. Fuel staging is the redistribution of fuel supply to exploit various mechanisms for the emission-safe operation of gas turbines at part load. Technical implementations of fuel staging are widely used in industry and are of high relevance for the present work. An overview of different fuelstaging strategies is given by Sattelmayer (2010). Technical concepts are often based on one or both of the following two mechanisms:

- In order to accomplish full burnout at part-load conditions, burners that operate below the lean blowout limit need to be ignited by pilots. Piloting is based on the phenomenon of self-ignition temperatures that are usually far below the adiabatic flame temperature (Sattelmayer, 2010).

- In multi-burner systems, it may be reasonable to supply only a fraction of all burners with fuel leading to locally increased temperatures and faster burnout downstream of the group of active burners. Note, quenching effects may occur at the interface to cold, inactive burners.

In this work, a modeling strategy is introduced that is able to capture both mechanisms. The model is based on a combustion model published by the authors in Klarmann, Sattelmayer, Geng et al. (2016) and Klarmann, Sattelmayer, Zoller et al. (2016). The combustion model is an extended version of the Flamelet Generated Manifold (FGM) and designed to achieve high accuracy in low-reactive conditions in which effects like flame stretch and/or heat loss may be relevant. It is important to note that a combustion model that is based on the flamelet assumption can only predict elevated $\mathrm{CO}$ emissions if the turbulent flame brush thickness is in the magnitude order of the combustion chamber or if the flamelets fluctutate to the outlet. As both assumptions are not realistic, it can be argued that the flamelet assumption is not valid when $\mathrm{CO}$ emissions occur. Furthermore, the prediction of CO using FGM requires excessive model tuning as it is shown by Goldin et al. (2012a, b). The authors concluded that FGM drastically overestimates the CO source term during burnout. Another attempt to numerically predict CO using CFD methods is done by Wegner et al. (2011), where CO is described by a 
transport equation that is decoupled from the combustion model. Within the turbulent flame brush, CO is initialized using the maximum value of $\mathrm{CO}$ at a predefined reaction progress. $\mathrm{CO}$ peak value is determined by onedimensional simulations based on detailed chemistry. The idea of separating the time scales of combustion and burnout is adopted in the present work. The CO model was firstly introduced and validated in an atmospheric single-burner test rig in Klarmann et al. (2018). In the following, this modeling strategy is extended to consider quenching effects that are demonstrated to play an important role in predicting $\mathrm{CO}$ emissions. Validation is performed using two multi-burner cases that differ in terms of pressure and the way fuel is staged in part load operation.

\section{Methodology}

In the following, the proposed CO-modeling approach is introduced. It is based on the combustion model that was published by the authors in Klarmann, Sattelmayer, Geng et al. (2016) and Klarmann, Sattelmayer, Zoller et al. (2016). We propose the employment of an isolated transport equation to describe the Favre-averaged mass fraction of $\mathrm{CO}$ :

$$
\frac{\partial \bar{\rho} \tilde{Y}_{\mathrm{CO}}}{\partial t}+\frac{\partial \bar{\rho} \tilde{u}_{i} \tilde{Y}_{\mathrm{CO}}}{\partial x_{i}}=\frac{\partial}{\partial x_{i}}\left(\frac{\mu_{t}}{S c_{t}} \frac{\partial \tilde{Y}_{\mathrm{CO}}}{\partial x_{i}}\right)+\overline{\dot{\omega}}_{\mathrm{CO}}
$$

The strategy for closing this equation is based on the spatial division into multiple zones in a way that is illustrated in Figure 1. A Lagrangian observer is shown that travels on a trajectory through a combustor and passes several regions. The observer's position determines the employed sub model for CO. In the lower half of Figure 1, a qualitative profile of $\mathrm{CO}$ as a function of the Lagrangian observer's travelled distance is shown. The continuous line represents $\mathrm{CO}$ predicted by the combustion model. As the Favre-averaged reaction progress $\tilde{c}$ reaches unity, the probability of flamelets is zero and $\mathrm{CO}$ is by definition in its equilibrium state. The dashed line shows the prediction by the CO model that is introduced in the present chapter. $\mathrm{CO}$ is described by the combustion model only up to a certain point, which is denoted as the decoupling event. The decoupling event marks the point at which the burnout chemistry cannot be described by flamelets anymore.

After CO is not described by the flamelet-based species trajectories (continuous line), CO oxidation becomes slower due to the absence of the flamelet's radical pool. Moreover, the post-flame model presented in this work loses its validity in situations in which the equivalence ratio is significantly decreased. In summary, four different regions of different modeling are defined:

- pre-flame zone: CO chemistry is negligibly small and we do not consider any source terms here.

- in-flame zone: Within the turbulent flame brush, chemical time scales are assumed to be smaller than turbulent time scales. We hence consider turbulent mixing to be the limiting mechanism and CO is described by

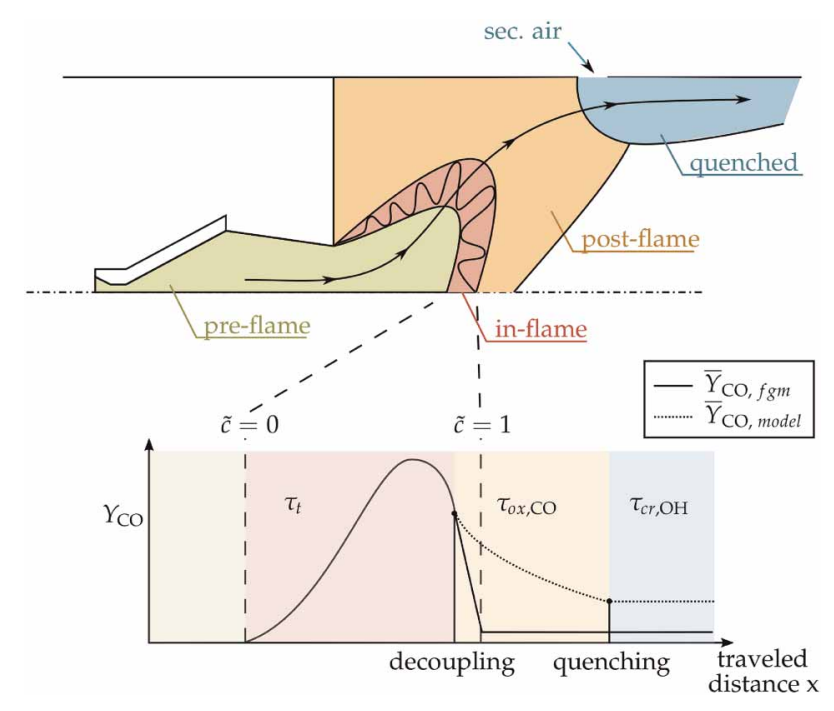

Figure 1. Illustration of the divide-and-conquer approach using a Lagrangian observer traveling trough a combustion chamber (adapted from Klarmann et al. [15]). 
flamelets. As shown by the authors in Klarmann et al. $(2018,2019)$, it is important to consider flame stretch as well as heat loss.

- post-flame zone: The interface between in- and post-flame zone is defined by the point at which the turbulent time scales are not the limiting factor anymore as chemical time scales become dominating. Details regarding modeling of the time scales is provided in the following.

- quenched zone: In the potential situation of lean quenching, the equivalence ratio is low and the chemical rates are negligibly small. As argued in the following, this region is dominated by the creation time scale of hydroxyl $(\mathrm{OH})$.

\section{Post-flame zone}

As it was shown in experiments by our group in Klarmann et al. (2019), freely propagating flamelets are not suitable to describe chemistry behind the turbulent flame brush. In general, burnout chemistry of $\mathrm{CO}$ can be described using a single reaction equation as mentioned by Turns (2000):

$$
\mathrm{CO}+\mathrm{OH} \rightarrow \mathrm{CO}_{2}+\mathrm{H}
$$

Reaction rates that are obtained from a zero-dimensional reactor simulation (Cantera (Goodwin et al., 2015)) are shown in Figure 2 at three different constant pressure conditions for an equivalence ratio of $\phi=0.3$. Note that merely the late burnout is plotted. As one can see, $\mathrm{CO}+\mathrm{OH} \rightarrow \mathrm{CO}_{2}+\mathrm{H}$ is always about two orders of magnitude greater than the second strongest reaction. It should be noted that these observations have also been made under different gas-turbine relevant conditions but are not shown in this paper due to the length restrictions. It is worth noting that closing the $\mathrm{CO}$ source term by using Equation 2 requires knowledge of the concentration of $\mathrm{CO}$ and $\mathrm{OH}$ as well as the non-adiabatic temperature (Arrhenius law). Temperature and $\mathrm{CO}$ concentration are known from their corresponding transport equations. $\mathrm{OH}$ is unknown and needs to be modeled. The use of a kinetic mechanism to evaluate $\mathrm{OH}$ would require to transport all participating species, leading to a tremendous increase in computational effort. Fortunately, $\mathrm{OH}$ kinetic mechanisms are not required, as discussed in the following. As frequently reported in literature, $\mathrm{OH}$ is in equilibrium during the burnout of $\mathrm{CO}$. For instance, Connors et al. (1996) assumes $\mathrm{OH}$ to be in equilibrium for the development of a semi-

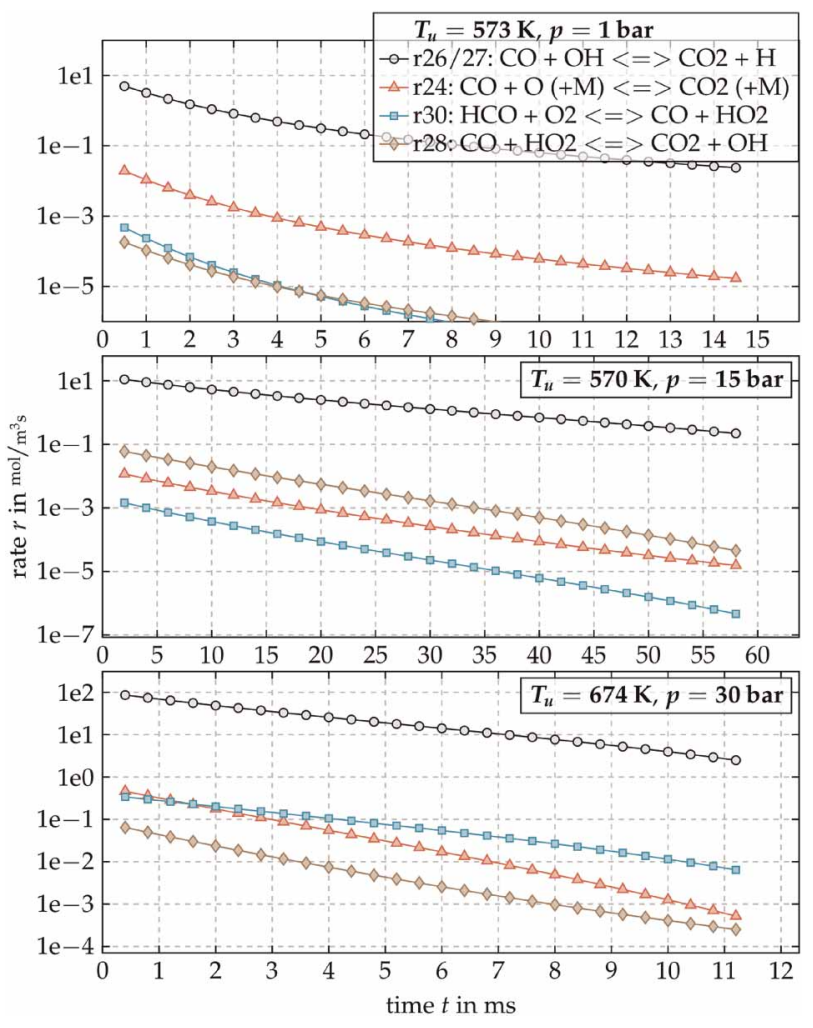

Figure 2. The four most relevant $\mathrm{CO}$ reactions in the late burnout (constant pressure reactor at an equivalence ratio of 0.3 calculated using Cantera [18]). 
empirical model to globally predict $\mathrm{CO}$ emissions in gas turbines. Using this assumption, the post-flame source term of $\mathrm{CO}$ can be evaluated using

$$
-\frac{d[\mathrm{CO}]}{d t}=k_{\text {arr }, \text { for }}(T)[\mathrm{CO}][\mathrm{OH}]_{e q}
$$

In the present work, the equilibrium of $\mathrm{OH}$ is determined using Galway 1.3 (Metcalfe et al., 2013) kinetics. Furthermore, $k_{\text {arr.for }}$ is calculated using Arrhenius parameters from Joshi and Wang (2006) that are also included in Galway 1.3. The model simplifications are further discussed and validated in the following. Flagan and Seinfeld (1988) compared time scales of different approaches for treating $\mathrm{OH}$ and $k_{\text {arr.for }}$. For this purpose, a characteristic time scale for the burnout of $\mathrm{CO}$ is defined:

$$
\tau_{\mathrm{CO}}=\frac{[\mathrm{CO}]}{k_{\text {arr for }}[\mathrm{CO}][\mathrm{OH}]}=\frac{1}{k_{\text {arr for }}[\mathrm{OH}]}
$$

$\tau_{\mathrm{CO}}$ as a function of equivalence ratio $\phi$ is plotted in Figure 3 (black line). Moreover, several models are reprinted and compared to the proposed post-flame model. The second model (red line) equals the approach in this work, as tabulated $\mathrm{OH}$ is assumed to be in equilibrium and $k_{\text {arr for }}$ is based on shock tube experiments. Note that deviations between the first two approaches (black and red line) may be related to different Arrhenius parameters for the evaluation of $k_{\text {arr.for }}$. Moreover, the third profile (blue line) represents a model by Fristrom and Westenberg (1965), which uses $\mathrm{OH}$ and $k_{\text {arr for }}$ that are fitted to experimental data. Note that this is in good agreement with the first two models indicating the validity of these approaches. The fourth model (brown line) was published by Howard et al. (1973) and uses reduced OH kinetics in combination with measured $k_{a r r}$ for. A significant underestimation of the $\mathrm{CO}$ burnout time in lean conditions by the fourth approach is evident. This indicates that the development of a reduced model may not lead to more accuracy than using $\mathrm{OH}$ in equilibrium. It is obvious that the reduced $\mathrm{OH}$ model is responsible for this inaccuracy as it is already proven by the first three models that a reduced CO model is able to achieve accurate results. The reason for this observation is that the $\mathrm{OH}$ chemistry is vast and cannot be reduced to a small set of equations without losing significant accuracy. Dryer and Glassman (1973) published a further strategy whereat $\mathrm{OH}$ and $k_{\text {arr for }}$ are measured within the turbulent flame brush (purple line). Estimation of the burnout time scale of $\mathrm{CO}$ by using in-flame $\mathrm{OH}$ leads to a significant underestimation by one to two orders of magnitude. This model can significantly be improved by replacing the in-flame $\mathrm{OH}$ with equilibrium $\mathrm{OH}$ (yellow line). It can be concluded that the in-flame chemistry of $\mathrm{CO}$ is solely faster due to elevated $\mathrm{OH}$. Note that this explains why flamelets or reactors should not be employed for the tabulation of $\mathrm{CO}$ burnout rates. A further finding is that $k_{\text {arr for }}$ seems to be valid, regardlessly if it is obtained in the in- or post-flame zone.

In order to prove the validity of the proposed post-flame model, we conducted atmospheric experiments. The geometry is depicted in Figure 4. Details to the experiment are show in Table 1. CO is measured by using a water-cooled probe at the indicated locations. Note that $\mathrm{CO}$ is measured and averaged at three different radii for each distance. The $\mathrm{CO}$ concentrations are used to derive source terms by using residence times between each distance that are retrieved from a corresponding CFD simulation (Fluent v.18 (ANSYS Inc., 2014)). In Figure 5, the resulting experimental CO source terms as a function of distance to the front plate are plotted. Moreover, experimental and numerical source terms are compared for two different adiabatic flame temperatures. The numerical $\mathrm{CO}$ source terms are calculated by using the proposed post-flame model (cf. Equation 3). After reaching a distance of $224.5 \mathrm{~mm}$, the post-flame model prediction and the experiments are in good agreement. It is apparent that the transition from the in- to the post-flame zone should be predicted to occur between $199 \mathrm{~mm}$ and $224.5 \mathrm{~mm}$. In addition, Figure 5 shows CO source terms obtained from a constant pressure reactor (blue dashed line) and from a freely-propagating flamelet (brown dashed line) at the corresponding reaction progress. Note that the experimental reaction progress source term can be derived from the measured carbon dioxide $\left(\mathrm{CO}_{2}\right)$ and $\mathrm{CO}$ concentrations. Both simulations drastically underestimate the source term due to the already discussed situation of elevated $\mathrm{OH}$ that is able to quickly burn out $\mathrm{CO}$.

\section{Modeling the transition to post-flame}

Models for closing CO within the flame and downstream of the turbulent flame brush are introduced in the previous sections. An additional model is needed to predict the reaction progress at which the transition from in- to post-flame occurs. A transition model is proposed by Wegner et al. (2011) in which CO is set to the maximum value of $\mathrm{CO}$ occurring in the flame front at a predefined reaction progress. This idea is simple and robust but has a 


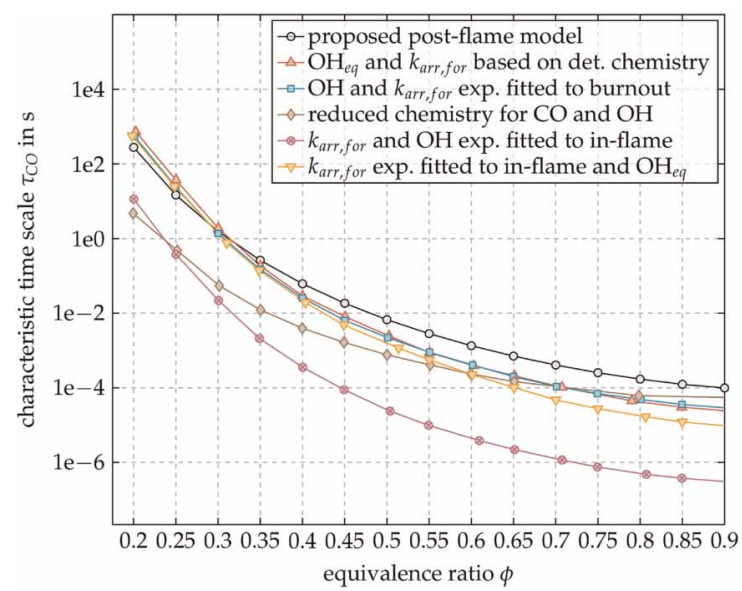

Figure 3. CO burnout time scales for different strategies of considering $\mathrm{OH}$ (reprinted and adapted from Flagan and Seinfeld [22]).

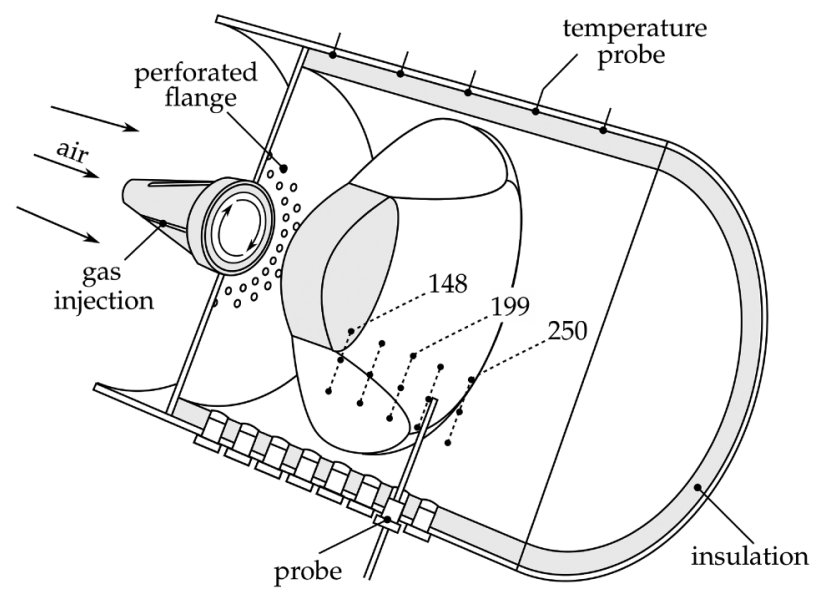

Figure 4. Illustration of the atmospheric single-burner test rig with indicated post-flame measurement locations.

Table 1. Experiment's boundary conditions.

\begin{tabular}{|c|c|}
\hline \multicolumn{2}{|l|}{ Boundary conditions } \\
\hline$T_{\infty}$ & $341 K$ \\
\hline$T_{\boldsymbol{u}}$ & $573.15 K$ \\
\hline$\lambda_{\text {wall }}, l_{\text {wall }}$ & $0.15 \mathrm{~W} / \mathrm{mK}, 2.8 \mathrm{~cm}$ \\
\hline$\dot{m}_{0}($ air $)$ & $32 \mathrm{~g} / \mathrm{s}$ \\
\hline$\dot{m}_{0, \mathrm{sec}}$ (air) & $30.2 \%$ of $\dot{m}_{0}$ \\
\hline$T_{a d}$ & $1521-1676 K$ \\
\hline \multicolumn{2}{|l|}{ CFD setup } \\
\hline software & Fluent v.18.0 [26] \\
\hline turbulence model & $k \epsilon$ realizable \\
\hline$S c_{t} / D a_{\mathrm{CO}, \text { crit }} / \xi_{\mathrm{OH}, \text { crit }}$ & $0.7 / 1 / 1$ \\
\hline mesh type & polyhedral \\
\hline mesh size (chamber) & $2.4 \mathrm{e} 5$ cells \\
\hline \multicolumn{2}{|l|}{ Table generation } \\
\hline kinetic & Galway 1.3 [20] \\
\hline discrete points $c / f / \psi / \kappa$ & $50 / 50 / 5 / \sim 5$ \\
\hline$m_{\kappa} / m_{\psi}$ & $2.38 / 0.38$ \\
\hline$m_{\kappa, \psi}$ & 1.87 \\
\hline
\end{tabular}


major simplification as it neglects the potential oxidation of $\mathrm{CO}$ within the turbulent flame brush before decoupling occurs. As demonstrated in the previous section, the flamelet-based oxidation of $\mathrm{CO}$ is usually significantly stronger than the burnout chemistry. Hence, a transition model is proposed that allows a fully flamelet-based closure in conditions in which the flamelet assumption is continuously valid during CO burnout. A suitable model for predicting the transition event needs to be based on a single criterion that unambiguously evaluates the validity of both the in- and the post-flame model. The criterion that is proposed in the following is modeled by comparing time scales. The in-flame model uses the assumption that all chemical time scales are faster than turbulent time scales. Furthermore, the post-flame zone is dominated by the slow burnout chemistry. The transition model in the present work is thus based on a Damköhler number that compares turbulent and chemical time scales:

$$
D a_{\mathrm{CO}}=\frac{\tau_{t}}{\tau_{o x, \mathrm{CO}}}
$$

Both time scales are specified in the following. A reasonable choice that we identified for the chemical scale is the time of oxidizing $\mathrm{CO}$ within the turbulent flame brush. It is approximated by assuming a bimolecular reaction (cf. Turns, 2000):

$$
\tau_{o x, \mathrm{CO}}=\frac{\ln \left(\frac{[\mathrm{CO}]}{\left[\mathrm{CO}_{e q}\right]}+\left(1-\frac{[\mathrm{CO}]}{\left[\mathrm{CO}_{e q}\right]}\right) \frac{[\mathrm{OH}]}{[\mathrm{CO}]}\right)}{([\mathrm{CO}]-[\mathrm{OH}]) k_{a r r, f o r}}
$$

The turbulent time scale can be interpreted as a characteristic time for micro-mixing and reads

$$
\tau_{t}=\frac{l_{\text {int }}}{u^{\prime}} \propto \frac{k}{\epsilon}
$$

In the context of RANS simulations, $k$ and $\epsilon$ can be derived from the turbulence model. The decoupling event is assumed to take place when $D a_{\mathrm{CO}}$ drops below a critical value. In this work, $D a_{\mathrm{CO}}$,crit is unity as this value marks the transition point when chemical time scales start exceeding turbulent time scales.

\section{Modeling lean quenching}

In order to guarantee low emissions at part load, gas turbines usually employ fuel staging concepts. Lean streaks may occur due to inactive burners, leakage air from sealings, and cooling air from liners. The mechanism of diluting the reactive flow to a level in which the reaction rates decrease to zero is denoted as lean quenching. Note that the combustion model, and consequently the in-flame model, are inherently able to consider lean quenching effects, as premixed counterflow flamelets can be calculated even for mixture fractions that are close to zero.

The proposed post-flame model is based on the assumption that $\mathrm{OH}$ is in equilibrium during burnout implying that the recreation of $\mathrm{OH}$ is always faster than the burnout of $\mathrm{CO}$. A numerical analysis of this simplification is demonstrated in Figure 6. The left y-axis shows the burnout time as a function of adiabatic flame temperature $T_{a d}$ (black line). For lean conditions, the burnout time steeply increases to values that are far above gas turbine combustor residence times. The ratio of $\mathrm{OH}$ creation to $\mathrm{CO}$ oxidation is plotted using the second y-axis (red line). For high adiabatic flame temperatures, the creation rate of $\mathrm{OH}$ is substantially higher than the oxidation rate of $\mathrm{CO}$, and the hypothesis that the equilibrium of $\mathrm{OH}$ can be reached is apparently valid. As the adiabatic flame temperature decreases, the ratio approaches unity (indicated by red dashed line). A ratio of unity implies that every produced $\mathrm{OH}$ molecule is used for the oxidation of $\mathrm{CO}$, as the creation of $\mathrm{OH}$ becomes the limiting factor. As mentioned before, the chemistry of $\mathrm{OH}$ is complex and hence difficult to model. Furthermore, the tabulation on the basis of detailed chemistry seems to be a potential solution. However, as it is discussed above, neither reactors nor flamelets are suitable downstream of the turbulent flame brush due to strongly increased $\mathrm{OH}$. A model for the prediction of the quenching event that is based on time scales is introduced in the following. Figure 7 shows the five most relevant reactions in which $\mathrm{OH}$ is involved for three different pressures for an equivalence ratio of $\phi=0.3$. The dominant reaction for all pressure conditions is the already introduced $\mathrm{CO}$ 


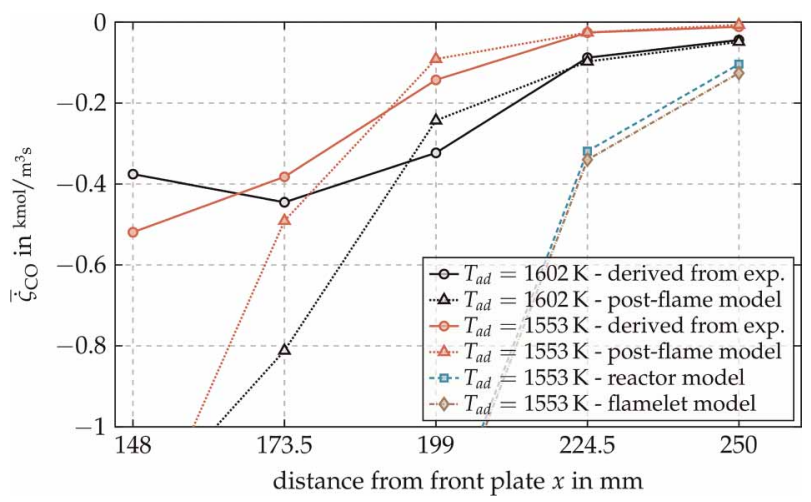

Figure 5. Comparison of experimental with modeled source terms of $\mathrm{CO}$.

burnout reaction. Moreover, the creation of $\mathrm{OH}$ is mainly based on three reactions:

$$
\begin{gathered}
\mathrm{H}+\mathrm{O}_{2} \leftrightarrow \mathrm{O}+\mathrm{OH} \\
\mathrm{HO}_{2}+\mathrm{OH} \leftrightarrow \mathrm{H}_{2} \mathrm{O}+\mathrm{O}_{2} \\
\mathrm{H}_{2} \mathrm{O}+\mathrm{O} \leftrightarrow 2 \mathrm{OH}
\end{gathered}
$$

In the following, it is assumed that all reactants on the left-hand side of this set of equations are in equilibrium and that solely the forward reaction is relevant. Note, the burnout of CO does not significantly alter dioxygen $\left(\mathrm{O}_{2}\right)$ and water $\left(\mathrm{H}_{2} \mathrm{O}\right)$ as both species are available in abundance. Fast time scales can be assumed for the following

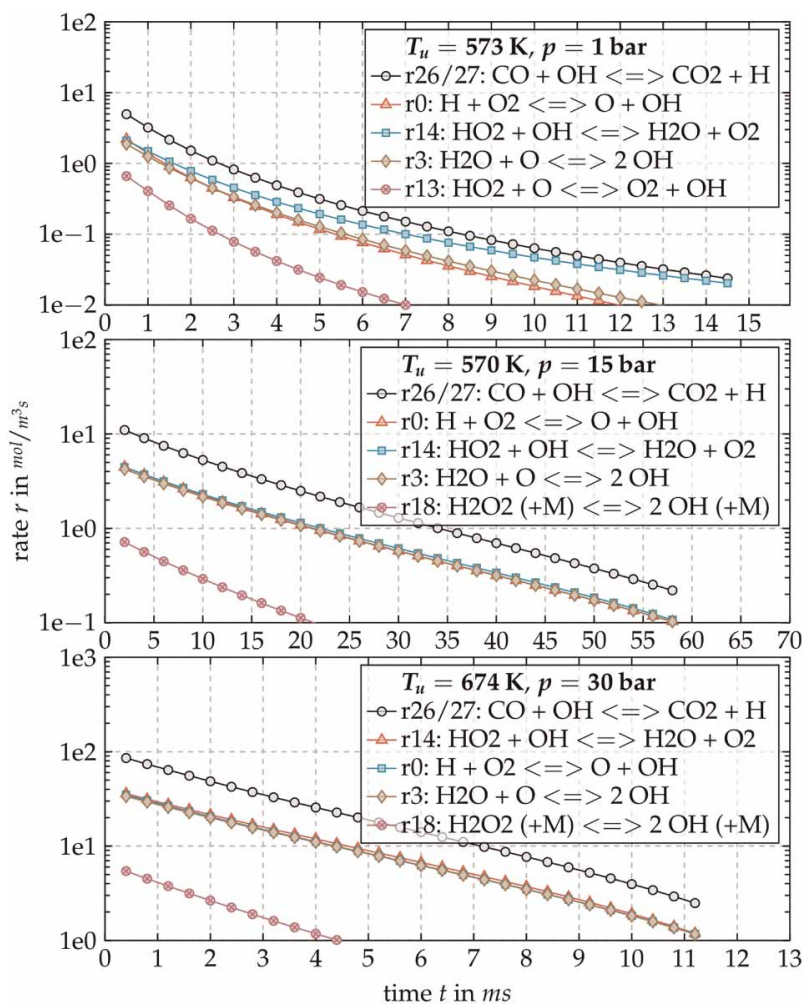

Figure 7. Five most relevant $\mathrm{OH}$ reactions in the late burnout (constant pressure reactor at an equivalence ratio of 0.3, calculated using Galway 1.3 [20] and Cantera [18]). 
radicals: Hydrogen $(\mathrm{H})$, oxygen $(\mathrm{O})$, and hydroperoxyl $\left(\mathrm{HO}_{2}\right)$. This leads to a model that allows to tabulate the $\mathrm{OH}$ creation rate $\dot{\zeta}_{c r, \mathrm{OH}}$ prior to the $\mathrm{CFD}$ simulation and to evaluate the $\mathrm{OH}$ creation time scale by using:

$$
\tau_{c r, \mathrm{OH}}=\frac{[\mathrm{OH}]}{\dot{\zeta}_{c r, \mathrm{OH}}}
$$

$\tau_{c r, \mathrm{OH}}$ is the built-up time for the equilibrium value of $\mathrm{OH}$ assuming the simplified creation rate. Furthermore, a dimensionless identifier is employed that describes the relationship between the time scales for $\mathrm{OH}$ creation and $\mathrm{CO}$ oxidation:

$$
\zeta_{\mathrm{OH}}=\frac{\tau_{c r, \mathrm{OH}}}{\tau_{o x, \mathrm{CO}}}
$$

A critical value of unity is used throughout the present work as this value implies the point at which $\mathrm{CO}$ oxidation exceeds $\mathrm{OH}$ creation.

\section{Validation}

The validation of two multi-burner cases that employ fuel staging concepts are presented in the following. Both cases use the GT11N silo combustor geometry that comprises 37 burners as illustrated in Figure 8. The first validation case is a down-scaled, atmospheric model of the GT11N. In addition, validation of a full-scale GT11N in field operation is presented. An overview of the numerical setups is given by Table 2. Both cases operate under part-load conditions in which solely a part of the total amount of burners is active. Multiple stages exist that differ in their number of active burners. A specified group of burners is switched off during the transition to a colder stage. By reducing the power to part load conditions, several stages are passed and the number of burners is successively reduced. The decisive difference between both fuel staging scenarios is the way fuel is reduced before a group of burners is switched off:

- Atmospheric GT11N model: A group of burners is ramped down from reference conditions to pure air. Variation of load during a stage is conducted by solely changing the fuel supply of the specific group that is intended to get switched off.

- High-pressure GT11N in field operation: The reduction of load is accomplished by decreasing the fuel supply for all active burners. This can be done until CO emissions increase to a specific limit. When this limit is reached, a group of burners that operates at stable conditions is abruptly switched off. The fuel surplus from the switched-off burners is redistributed to the remaining group of active burners leading to a drop in CO emissions.

All introduced models are implemented in Fluent v.18 (ANSYS Inc., 2014). The shown results are retrieved from a steady, pressure-based RANS CFD simulation.

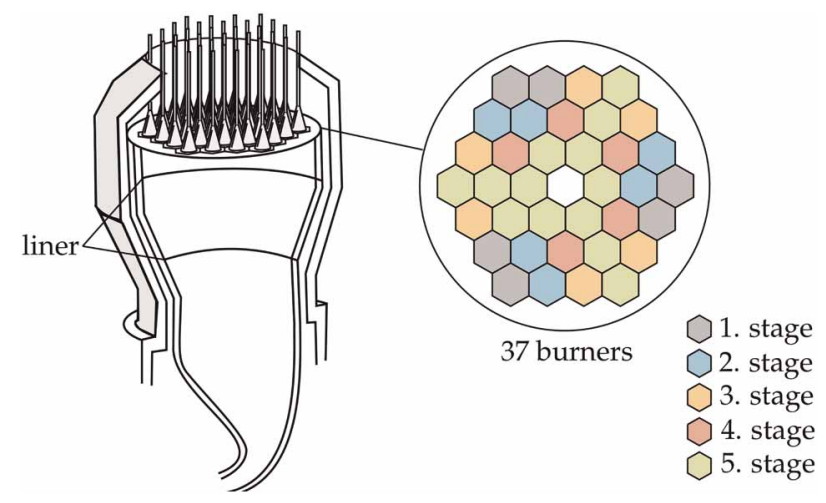

Figure 8. Illustration of the GT11N (inspired by Vorontsov et al. [27]) emphasizing the employed fuel staging concept of the atmospheric case. 
Table 2. Setup for the multi-burner cases.

\begin{tabular}{|c|c|}
\hline \multicolumn{2}{|l|}{ CFD setup } \\
\hline software & Fluent v.18.0 [26] \\
\hline turbulence model & $k \epsilon$ realizable \\
\hline$S c_{t} / D a_{\mathrm{CO}, \text { crit }} / \xi_{\mathrm{OH}, \text { crit }}$ & $0.7 / 1 / 1$ \\
\hline mesh type & tetrahedral \\
\hline mesh size (chamber) & $1.9 \mathrm{e} 7$ cells \\
\hline \multicolumn{2}{|c|}{ Atmospheric model of the GT11N } \\
\hline$m_{\kappa} / m_{\psi}$ & $2.35 / 0.37$ \\
\hline \multicolumn{2}{|l|}{ GT11N in field operation } \\
\hline$m_{\kappa}$ & 2.94 \\
\hline
\end{tabular}

\section{Atmospheric GT11N model}

The validation of a down-scaled, atmospheric model of the GT11N is presented in the following. The experimental data is retrieved from an unpublished, company-internal measurement study that was conducted in order to find reasonable fuel staging strategies for silo combustors. In the report, the optimal concept for part-load operation is investigated in terms of how the burners should be grouped and in which order the groups should be phased out when reducing the load. The burner grouping is depicted in Figure 8 (illustration inspired by Vorontsov et al., 2009). It is important to note that this burner grouping is not a reasonable strategy for real gas turbines and should be interpreted as a benchmark test in terms of $\mathrm{CO}$ emissions. For example, the last group of burners that remains active for the coldest conditions (stage 5) is the most critical group. A reasonable strategy would be to locate the active burners of stage 5 in a way that the number of cold neighbours is minimized. However, the burners of stage 5 are far apart from each other, have many cold neighbours, and are hence not optimal in terms of CO emissions in part load.

Unfortunately, the exact geometry of the atmospheric model of the GT11N is not available. However, the geometry of the full-size GT11N is employed and geometrically scaled down to fit the combustion chamber's diameter of the atmospheric model. The geometry comprises the plenum, all burners, the combustion chamber, and the transition piece. $\mathrm{CO}$ mole fraction $X_{\mathrm{CO}}$ as a function of adiabatic flame temperature $T_{a d}$ is plotted in Figure 9. Four stages are indicated. In each stage, a specified group of burners is ramped down from reference conditions to pure air. The hot conditions of the first stage lead to fast $\mathrm{CO}$ burnout. Hence, measured $\mathrm{CO}$ (black line) as well as modeled CO (red line) are close to equilibrium. In the second stage, CO emissions rise by reducing the fuel supply of the specified group of burners (orange burners) from $100 \%$ to $50 \%$. This mechanism is shown by the first two contour plots of Figure 10. Moreover, reducing the fuel supply from $50 \%$ to $0 \%$ leads to a decrease of $\mathrm{CO}$ emissions. Here, the specified group of burners operates below lean blowout limit and are piloted by the active group (red burners). This mechanism is shown in the third contour plot of Figure 10. The decline in $\mathrm{CO}$ with decreasing fuel supply is based on the mechanism that the amount of carbon atoms decreases with fuel supply. The third stage also shows an increase of $\mathrm{CO}$ emissions when the burners are reduced in fuel supply. A decisive difference between the second and the third stage is that the global CO emissions do not decline after the specified group of burners is phased out. At this point, the burnout of the active burners cannot be achieved anymore. In the fourth stage, the typical rise and fall of $\mathrm{CO}$ emissions during the process of phasing out a group of burners is shown. The proposed CO model strategy is capable of meeting the global CO measurements of the second and third stage. In the fourth stage, experimental $\mathrm{CO}$ declines after a local maximum was reached. The experimental profile of the fourth stage cannot be predicted by the proposed modeling strategy as $\mathrm{CO}$ proceeds rising instead of dropping as it is observed in the experiments. $\mathrm{CO}$ predicted by the flamelets (blue line) is tremendously underestimating global CO. 


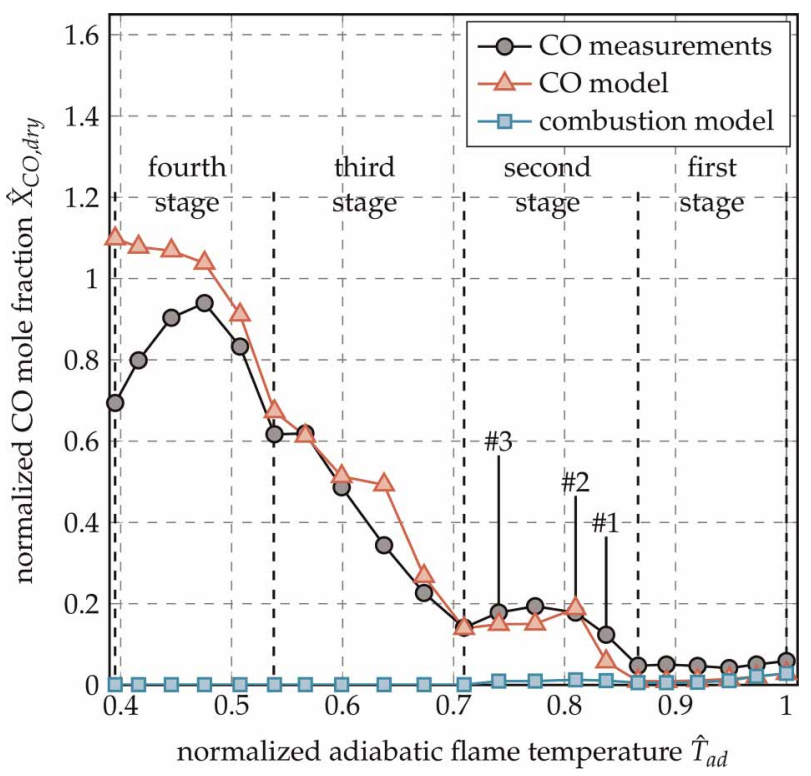

Figure 9. Temperature dependent CO emissions of the atmospheric GT11N model.
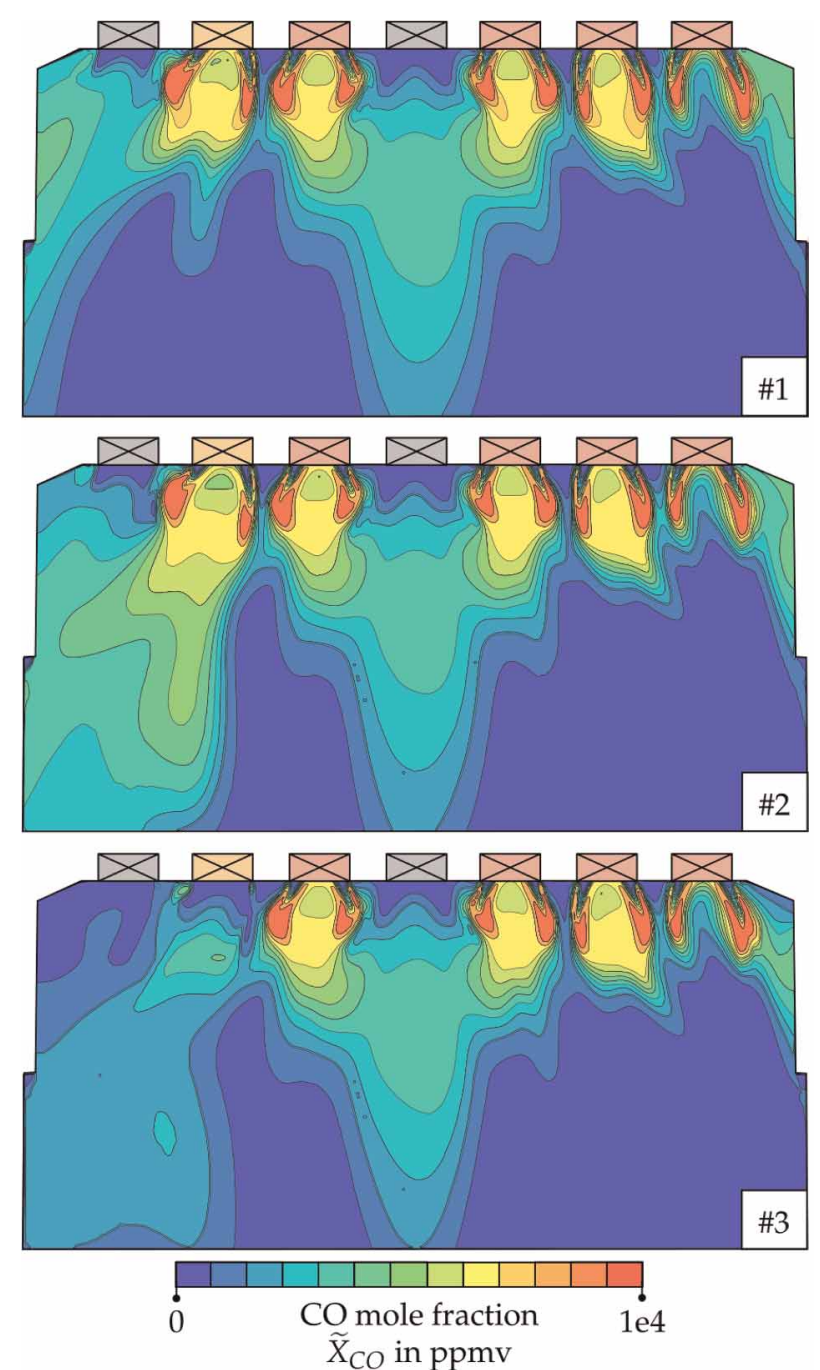

Figure 10. Contour plots of CO mole fractions of three characteristic loads of the atmospheric GT11N model. 


\section{High-pressure GT11N in field operation}

The burner layout that is used in the high-pressure case is illustrated in Figure 11. 31 single switchable burners are belonging to the main group (red burners). The central burner is not active for the operating points that are considered in this study. Six burners of the piloted group (orange burners) are located in each corner. Piloted burners are supplied with substantially less fuel than burners that belong to the main group. Figure 12 demonstrates the interaction between the two groups. The first contour plot shows the laminar flame velocity $s_{l}$. It can be seen that burners of the piloted group (orange) are operated with laminar flame velocities that are close to zero and are thus not able to provide a stable flame. Nevertheless, burnout can be achieved as adjacent active burners from the main group are able to burnout the cold flow of the piloted group. The second contour plot of Figure 12 shows the interaction of active burners with an inactive burner (grey burner) that is located in the center. It is apparent that the cold central burner has a strong impact on the CO emissions. The third contour plot shows the result when the quenching model is deactivated in order to demonstrate its significant impact on CO oxidation.

Validation is performed by comparing modeled with measured $\mathrm{CO}$ emissions as function of adiabatic flame temperature $T_{a d}$ in Figure 13. Numerical results (red line) are in good agreement with the measured data (black line). The proposed modeling strategy is apparently able to quantitatively predict the absolute $\mathrm{CO}$ emissions, as well as the influence of burner switch-off events on CO. A decreased model accuracy can be observed in very lean conditions that was already discussed above. Additionally, predictions from the flamelet-based combustion model are plotted (blue line). As expected, the flamelets do not reach the combustor's outlet and CO is drastically underestimated.

\section{Summary and discussion}

Model validation for the numerical prediction of CO emissions in gas turbine combustors featuring multiple burners operating under part load conditions is presented in this paper. The modeling approach divides the domain in multiple regions and models each section differently. The model's capacity to capture the following phenomena is demonstrated:

- Typical behaviour of global CO emissions as a function of adiabatic flame temperature.

- Piloting of premixed flames that are operated below the lean blow out limit.

- Lean quenching of flames interacting with colder neighbours.

The modeling strategy is validated with CO emissions obtained by comparing numerical results to two different cases. An accurate prediction of the $\mathrm{CO}$ emissions without model tuning is achieved. Furthermore, the poor performance of the flamelet-based combustion model is demonstrated.

The modeling strategy of the present work exhibits two points of potential criticism that are addressed in the following:

- The proposed modeling strategy is based on the comparison of time scales to predict the different zones in which the submodels are used. A valid criticism would be that the times scales should not be interpreted in an absolute way. For instance, the circumferential speed of eddies do not have an direct relationship to the $\mathrm{CO}$ burnout time but both quantities are compared to predict the transition from in- to post-flame. However, this approach should be reasonable if at least one of the following situations is true:

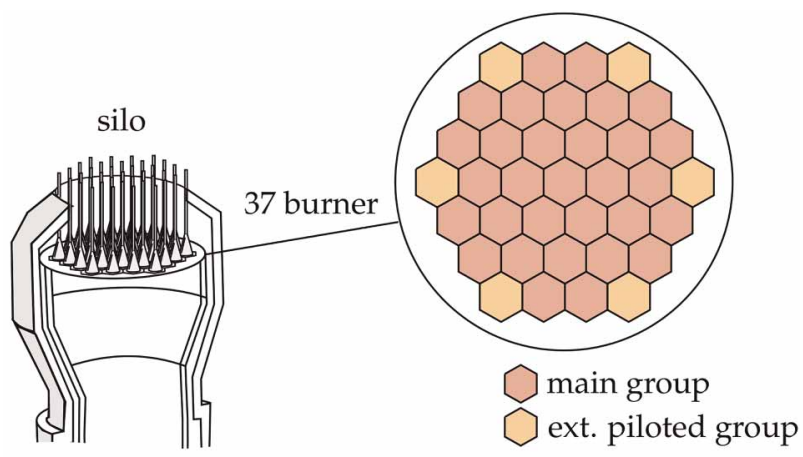

Figure 11. Burner layout of the high-pressure GT11N in field operation. 

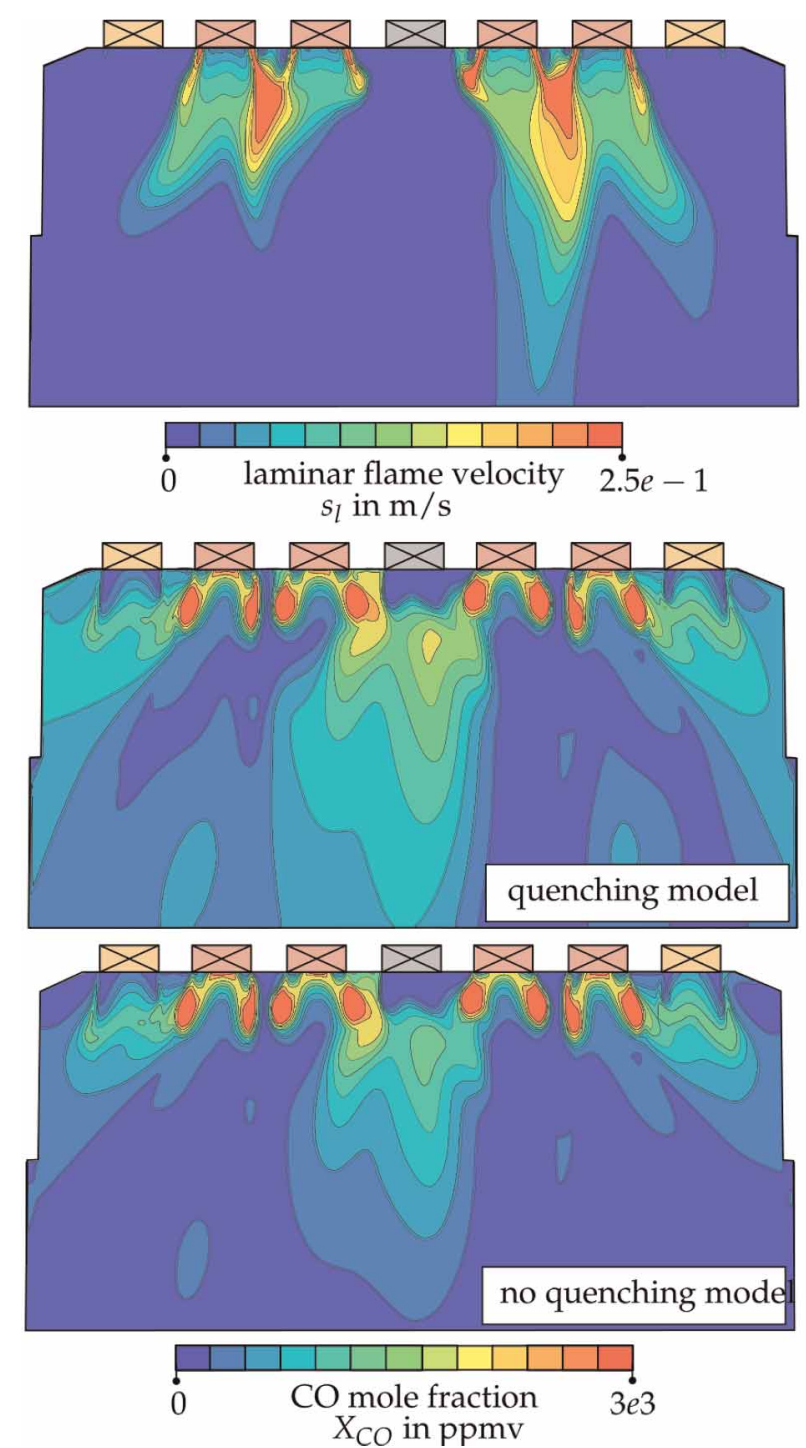

Figure 12. Contour plots of the high-pressure GT11N in field operation.

- $D a_{\mathrm{CO}}$ does significantly change within the turbulent flame brush. Different values for $D a_{\mathrm{CO} \text {,crit }}$ do not substantially alter the position of the decoupling event as long as the threshold is in the magnitude order of unity.

o There is a transition area in which the in- and post-flame model show similar source terms for CO reducing the error of a wrongly predicted decoupling event.

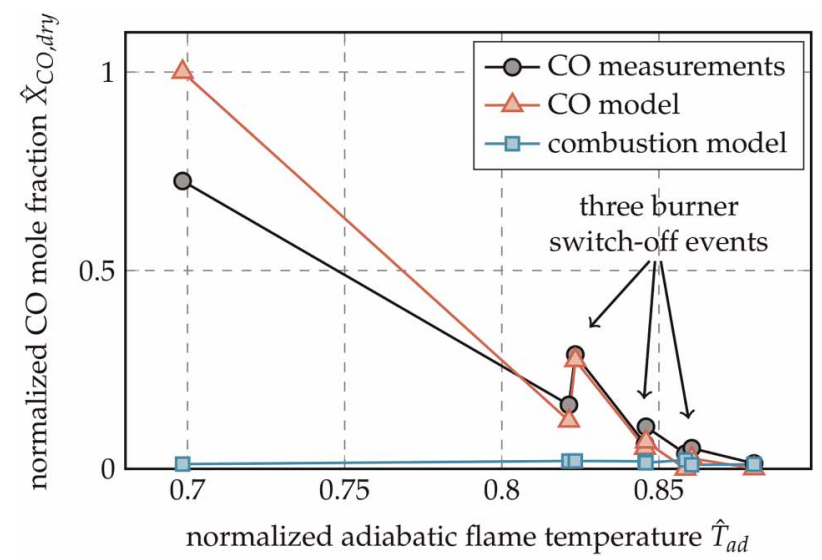

Figure 13. Temperature dependent CO emissions of the high-pressure GT11N in field operation. 
- Turbulence-chemistry interaction is neglected during burnout. This is only valid if one or both of the two situations apply:

- CO burnout is slow and the variance of CO mass fraction is close to zero. This means that the PDF collapses to a singularity at the corresponding mean value and a PDF integration has no effect.

o Non-zero variances of $\mathrm{CO}$ mass fraction do not imperatively lead to the necessity of employing PDF integration. This is due to the fact that $\mathrm{CO}$ burnout chemistry can be assumed to behave linearly in the range of small variances.

\section{Nomenclature}

\section{Miscellaneous}

(...) Favre averaging

$\overline{(\ldots)}$ Reynolds averaging

$(\ldots)^{\prime}$ Root mean square

[...] Concentration, $\mathrm{kmol} / \mathrm{m}^{3}$

\section{Latin}

c Reaction progress, -

$D a_{\text {CO }}$ Model specific Dammköhler number, -

$f$ Mixture fraction, -

$k_{\text {arr }}$ Reaction rate constant

$k \quad$ Turbulent kinetic energy, $\mathrm{m}^{2} / \mathrm{s}^{2}$

$l_{\text {int }} \quad$ Integral length scale, $m$

$l_{\text {wall }}$ Wall thickness, $m$

$\dot{m} \quad$ Mass flow, $\mathrm{kg} / \mathrm{s}$

$m_{\kappa} \quad$ Proportionality exponent for stretch correction, -

$m_{\psi} \quad$ Proportionality exponent for non-adiabatic correction, -

$p \quad$ Pressure, bar

$r \quad$ Reaction rate, $\mathrm{mol} / \mathrm{m}^{3} \mathrm{~s}$

$s_{l} \quad$ Laminar flame velocity, $\mathrm{m} / \mathrm{s}$

$S c_{t} \quad$ Turbulent Schmidt Number, -

$t \quad$ Time, $s$

$T$ Temperature, $K$

$u \quad$ Velocity, $\mathrm{m} / \mathrm{s}$

$x \quad$ Spatial coordinate, $m$

$X_{i} \quad$ Mole fraction of species $i, \mathrm{~mol} / \mathrm{mol}$

$Y_{i} \quad$ Mass fraction of species $i, \mathrm{~kg} / \mathrm{kg}$

\section{Greek}

$\dot{\zeta}$ Molecular source term, $\mathrm{kmol} / \mathrm{m}^{3} \mathrm{~s}$

$\epsilon \quad$ Turbulence dissipation rate, $\mathrm{m}^{2} / \mathrm{s}^{3}$

$\kappa \quad$ Stretch, $1 / s$

$\mu_{t} \quad$ Turbulent viscosity, $\mathrm{kg} / \mathrm{ms}$

$\rho \quad$ Density, $\mathrm{kg} / \mathrm{m}^{3}$

$\lambda$ Thermal conductivity, $\mathrm{W} / \mathrm{mK}$

$\tau$ Timescale, $s$

$\phi \quad$ Equivalence ratio

$\zeta_{\mathrm{OH}}$ Model specific identifier, -

$\dot{\omega} \quad$ Source term, $\mathrm{kg} / \mathrm{m}^{3} \mathrm{~s}$ 


\section{Funding sources}

The investigations were conducted as part of the joint research program COORETEC-turbo (AG Turbo 2020) in the frame of AG Turbo. The work was supported by the Bundesministerium für Wirtschaft und Technologie (BMWi) as per resolution of the German Federal Parliament under grant number 03ET7071H. The authors gratefully acknowledge AG Turbo and GE Power for their support and permission to publish this paper. The views and opinions expressed in this paper are those of the author only and do not necessarily reflect the views of or should they be attributed to General Electric Company.

\section{Competing interests}

Noah Klarmann declares that he has no conflict of interest. Thomas Sattelmayer declares that he has no conflict of interest.

\section{References}

ANSYS (2014). ANSYS Fluent Academic Research, Relase 18.0.

British Petroleum (BP) (2018). Energy Outlook. https:/www.bp.com/content/dam/bp/en/corporate/pdf/energy-economics/energy-outlook/ bp-energy-outlook-2018.pdf

Connors C. S., Barnes J. C., and Mellor A. M. (1996). Semiempirical predictions and correlations of CO emissions from utility combustion turbines. Journal of Propulsion and Power. 12 (5): 926-932. https://doi.org/10.2514/3.24124.

Dryer F. L., and Glassman I. (1973). High-temperature oxidation of CO and CH4. Symposium (International) on Combustion. 14 (1): 987-1003. https://doi.org/10.1016/S0082-0784(73)80090-6.

Flagan R., and Seinfeld J. (1988). Fundamentals of Air Pollution Engineering. 1st edn. New Jersey: Prentice Hall. https://doi.org/10. 1007/SpringerReference_29442.

Fristrom R. M., and Westenberg A. A. (1965.) Flame Structure. 1st edn. New York City: McGraw-Hill.

Goldin G. et al. (2012a). Modeling CO With Flamelet-Generated Manifolds: Part 1 - Flamelet Configuration. In: Proceedings of the ASME Turbo Expo 2012, GT2012-69528, Copenhagen, pp. 1-11. https://doi.org/10.1115/GT2012-69528.

Goldin G. et al. (2012b). Modeling CO With Flamelet-Generated Manifolds: Part 2 - Application. In: Proceedings of the ASME Turbo Expo 2012, GT2012-69546, Copenhagen, pp. 1-8. https://doi.org/10.1115/GT2012-69546.

Goodwin D. et al. (2015). Cantera: An Object-Oriented Software Toolkit for Chemical Kinetics, Thermodynamics, and Transport Processes retrieved from code.google.com/p/cantera. code.google.com/p/cantera

Howard J. B., Williams G. C., and Fine D. H. (1973). Kinetics of carbon monoxide oxidation in postflame gases. Symposium (International) on Combustion. 14 (1): 975-986. https://doi.org/10.1016/S0082-0784(73)80089-X.

International Energy Agency (IEA) (2014). World Energy Outlook 2014 - Factsheet.

International Energy Agency (IEA) (2017). World Energy Outlook 2017 - Executive Summary. https://doi.org/10.1016/0301-4215(73)90024-4.

Joshi A. V., and Wang H. (2006). Master equation modeling of wide range temperature and pressure dependence of $\mathrm{CO}+\mathrm{OH}$ to products. International Journal of Chemical Kinetics. 38 (1): 57-73. https://doi.org/10.1002/kin.20137.

Klarmann N., Sattelmayer T., Geng W. (2016). Flamelet Generated Manifolds for Partially-Premixed, Highly-Stretched and Non-Adiabatic Combustion in Gas Turbines. In: AIAA Science and Technology Forum and Exposition - SciTech 2016, San Diego, pp. 1-14. https://doi.org/10.2514/6.2016-2120.

Klarmann N., Sattelmayer T., Zoller B. T. (2016). Impact of Flame Stretch and Heat Loss on Heat Release Distributions in Gas Turbine Combustors: Model Comparison and Validation. In Proceedings of the ASME Turbo Expo 2016, GT2016-57625, pp. 1-12. https://doi.org/10.1115/gt2016-57625.

Klarmann N., Zoller B. T., and Sattelmayer T. (2018). Numerical modeling of CO-emissions for gas turbine combustors operating at part-load conditions. Journal of the Global Power and Propulsion Society. 2 (1): 376-387. https://doi.org/10.22261/jgpps.c3n5oa.

Klarmann N., Zoller B. T., and Sattelmayer T. (2019). Modeling of CO Emissions in Multi-Burner Systems with Fuel Staging. In: Proceedings of ASME Turbo Expo 2019, Phoenix, pp. 1-12. https://doi.org/10.1115/gt2019-90821.

Lefebvre A. H., and Ballal D. R. (2010.) Gas Turbine Combustion - Alternative Fuels and Emissions. 3rd edn. Boca Raton: Taylor \& Francis Group.

Metcalfe W. K., et al. (2013). A hierarchical and comparative kinetic modeling study of C1-C2 hydrocarbon and oxygenated fuels. International Journal of Chemical Kinetics. 45 (10): 638-675. https://doi.org/10.1002/kin.20802.

Möning R. and Waltke U. (2010). Verdichter. In: Stationäre Gasturbinen. 2nd edn. edited by Lechner, C., and Seume, J. Berlin: Springer-Verlag Berlin Heidelberg. 313-369.

Sattelmayer T. (2010). Grundlagen der Verbrennung in stationären Gasturbinen. In: Stationäre Gasturbinen. 2nd edn. edited by Lechner, C., and Seume, J. Berlin: Springer-Verlag Berlin Heidelberg. 397-453.

Sinn H. W. (2017). Buffering volatility: A study on the limits of germany's energy revolution. European Economic Review. 99: 130-150. https://doi.org/10.1016/j.euroecorev.2017.05.007.

Turns S. R. (2000.) An Introduction to Combustion - Concepts and Applications. 2nd edn. Singapore: McGraw-Hill.

U.S. Energy Information Administration. (2017). International Energy Outlook 2017, International Energy Outlook.

Vorontsov S. et al. (2009). Alstom GT11N2 M Expansion Turbine Design Modification and Operation Experience. In: Proceedings of the ASME Turbo Expo 2009, GT2009-59268, Orlando, pp. 1-9.

Wegner B., et al. (2011). CFD prediction of Partload CO emissions using a two-timescale combustion model. Journal of Engineering for Gas Turbines and Power. 133 (7): 071502-1-7. https://doi.org/10.1115/1.4002021.

Wiedermann A. (2010). Gasturbinentypen- eine Übersicht. In: Stationäre Gasturbinen. 2nd edn. edited by Lechner, C., and Seume, J. Berlin: Springer-Verlag Berlin Heidelberg, pp. 1-11. 